Session 2532

\title{
Five Years from a Second ABET EC2000 General Review - and Counting
}

\author{
David L. Soldan, Donald H. Lenhert, and Andrew Rys \\ Electrical and Computer Engineering \\ Kansas State University
}

\begin{abstract}
Many engineering programs would still like to operate in the mode of ignoring Accreditation Board for Engineering and Technology (ABET) issues except for the year prior to a visit. With the emphasis on continuous quality improvement inherent in Engineering Criteria $2000^{1}$ (EC2000) this is a dangerous mode of operation. Instead of back to business as usual after a visit, it is now necessary to have ongoing activity focused on preparation for the next visit.
\end{abstract}

\section{Introduction}

The electrical engineering and computer engineering programs at Kansas State University were visited under EC2000 on a general review during the Fall 1999 accreditation cycle. Given the time frame for implementation of the new criteria it was necessary to rely heavily on processes that were in place prior to the release of the EC2000 criteria ${ }^{2}$. While many of these processes had been in place for several years they didn't necessarily directly address all of the issues required by Criteria 2, Program Educational Objectives and Criteria 3, Program Outcomes and Assessment of EC2000.

To prepare for the next general review the Electrical and Computer Engineering Department (EECE) faculty felt it would be best to do a complete evaluation of the mission and educational objectives of the programs. This could involve some changes in existing data gathering and analysis processes. Our long term plan is to have a comprehensive review of the program educational objectives on a six year cycle.

The next activity is the reevaluation of the processes by which the program outcomes are determined and results evaluated. Inherent in this will be a review of current program outcomes for each program. The plan is to finish this activity in time to allow at least three years prior to the next general review. This would allow for data regarding any new outcomes to be gathered and analyzed.

A key goal of these efforts is to structure all processes in such a way as to make them part of everyone's normal operation and to minimize the impact of these processes on faculty time. We 
hope that this will continue to change how faculty and students view accreditation. The desired end result is that all faculty and students will operate in the continuous improvement mode and not think of accreditation as "something extra that happens every six years."

\section{Educational Objectives}

Our first step in preparation for the next general review is to do a complete evaluation of the mission and educational objectives of the programs. This could involve some changes in existing data gathering and analysis processes. Analysis of data gathered from our primary constituencies over the last three years would form the starting point for this effort. The primary constituencies include students, alumni, industry and government, the university, and the faculty.

To start this process the course and curriculum committees for the two programs had a series of joint meetings to discuss the current mission statement and educational objectives. The joint committee examined the requirements of Criterion 2, Program Educational Objectives, and looked at feedback from alumni, government, and industry. They also looked at the work done at the National Science Foundation (NSF) Faculty Workshops and National Electrical Engineering Department Heads Association (NEEDHA) ABET workshops that have been conducted over the last two years.

There has been a great deal of discussion on what program educational objectives are and how they differ from program outcomes. The NSF Faculty Workshops tried to clarify this with the following two definitions ${ }^{3}$ :

Program Educational Objectives - Statements that describe the expected accomplishments of graduates during the first few years after graduation. This definition assumes that audiences are external and there are two types of objectives - 1) those that all students are expected to achieve, and 2) those that some students are expected to achieve.

Program Outcomes - Statements that describe what students are expected to know and are able to do by the time of graduation.

These are limited definitions and have not been endorsed by either ABET or NSF. It is hoped that they help differentiate between the requirements of Criterion 2 and Criterion 3. Every institution is free to define its own terminology.

Given the information gathered and using the definitions above, the joint committee attempted to write a new set of program educational objectives for each program. These objectives would provide outside audiences a definition of what makes our programs unique. This information was then presented to the faculty of the EECE Department. At this time we are having ongoing

Proceedings of the 2001 American Society for Engineering Education Annual Conference and Exposition Copyright (C) 2001, American Society for Engineering Education 
discussions concerning both the definition of objectives and the program educational objectives.

Our goal is to complete this review by the summer of 2001 which is four years prior to the next general review. This would include having feedback from the EECE Advisory Council and selected other outside constituents. Our long term plan is to have a comprehensive review of the program educational objectives on a six year cycle. This review would be initiated upon receipt of the results of each general review by ABET.

\section{Program Outcomes and Assessment}

After the program objectives have been modified and approved the next activity is the reevaluation of the processes by which the program outcomes are determined. This will be followed by a review of current program outcomes for each program. Again the inclusion of input from all constituencies is necessary. It will be extremely important to find ways to measure student achievement of each of the outcomes, including some of the so-called "soft outcomes" like those dealing with teamwork and lifelong learning.

The concept that outcomes are those things that students can do prior to graduation indicates that achievement of program outcomes should be measurable while students are still in school. Outcomes assessment processes will determine the level of achievement of current students. It is expected that proper structuring of learning experiences and of individual class assessment instruments will play a large role in outcomes assessment. This is a key element in making the outcomes assessment part of the everyday operation of the faculty.

The updating of the program outcomes will be the focus of the 2001-2002 academic year which will allow at least three years prior to the next general review. This time will allow for data regarding any new outcomes to be gathered, analyzed, and used to make improvements. The long term plan is that the curriculum committees will collect and analyze outcomes assessment data on an annual basis. This will drive change in both what the outcomes are and how we try to achieve those outcomes.

\section{Other issues}

The format of final accreditation reports addresses several issues: strengths; concerns; weaknesses; deficiencies; and observations. While each of these has different effects on the accreditation action, they all provide feedback on the program that was visited. These statements should all be used in the process of reviewing educational objectives and program outcomes. The fact that each of the statements given has been reviewed and considered by the appropriate constituencies should be documented. The report for a second visit will be expected to contain details of how each shortcoming (concern, weakness, deficiency) from the previous visit was dealt with. 


\section{Conclusions}

Successful preparation for a second visit under EC2000 can be facilitated by focusing on a few key factors:

- Develop clear definitions of objectives and outcomes

- Inclusion of all constituent groups in the process of setting educational objectives and program outcomes

- $\quad$ Making program outcomes assessment part of the normal process of teaching

- $\quad$ Insure use of and response to previous shortcomings

It appears that EC2000 offers great opportunities for programs to uniquely define themselves and continue to provide engineering education that is applicable to the rapidly changing environment in which we operate.

Bibliography

1. Criteria for Accrediting Engineering Programs, Engineering Accreditation Commission, Accreditation Board for Engineering and Technology, November 1, 1999.

2. Soldan, D., Alumni Assessment in the ABET 2000 Environment, Proceedings of the $27^{\text {th }}$ Frontiers in Education Conference, Pittsburgh, Pennsylvania, November 1997.

3. Avers, C. D., Criteria 2000: Lessons Learned, The Interface, Newsletter of the IEEE Education Society and ASEE Electrical and Computer Engineering Division, August 1999.

\section{DAVID L. SOLDAN}

David L. Soldan is Professor and Head of Electrical and Computer Engineering at Kansas State University. He is a member of the IEEE Committee on Engineering Accreditation Activities where he is active in new program evaluator training and mentoring. He has served on the IEEE Education Society Adcom and has been the IEEE Computer Society representative to the Frontiers in Education Conference Steering Committee.

\section{DONALD H. LENHERT}

Donald H. Lenhert in Professor of Electrical and Computer Engineering at Kansas State University. He serves as Chair of the Computer Engineering Curriculum Committee. He has developed and taught the microprocessor design course since the middle 1970's. He is working on an NSF CRCD grant on real-time embedded systems. Dr. Lenhert edits the IEEE Test Technology Technical Council Newsletter for IEEE Design and Test of Computers.

\section{ANDREW RYS}

Andrew Rys is Professor of Electrical and Computer Engineering at Kansas State University. He serves as Chair of the Electrical Engineering Curriculum Committee. Dr. Rys has been teaching courses in electronics, optoelectronics, integrated circuit design, and solid-state electronic devices. His current research interests are mainly concerned with electrical characterization of wide bandgap semiconductors.

Proceedings of the 2001 American Society for Engineering Education Annual Conference and Exposition Copyright (C) 2001, American Society for Engineering Education 